\title{
A comparison of signaled vs. unsignaled free-operant avoidance in Mongolian gerbils and domesticated rats
}

\author{
ROBERT W. POWELL, MICHAEL D. CURLEY, and LINDA J. PALM \\ University of South Florida, Tampa, Florida 33620
}

\begin{abstract}
The performance of gerbils, hooded rats, and albino rats was compared under signaled and unsignaled free-operant leverpress avoidance. Within-groups comparisons revealed that asymptotic shock rates did not differ for either domestic rat strain between signaled and unsignaled conditions; gerbils received significantly fewer shocks when the signal was present. Betweengroups comparisons showed that gerbils received fewer shocks than either rat strain under the signaled condition and fewer shocks than the hooded rats under the unsignaled condition. All groups had substantially lower response rates when the signal was present. In addition, all groups made many more responses, proportionally, during the period preceding shock when the signal was present than when it was absent. An explanation of these findings is proposed that emphasizes differences in selective processes that operate upon wild stocks in comparison to domesticated species.
\end{abstract}

Does the presence of a preaversive signal affect avoidance responding in rodents in comparison to an unsignaled procedure? The answer to this question is unequivocally yes. Does the change in responding result in reduced shock rates? Although the answer to this question is generally affirmative (Gilbert, 1971; Keehn, 1959; Myers, 1964, 1977; Sidman, 1955), a number of studies indicate that procedural, parametric, and species variables can have potent effects. With respect to the latter point, we have recently reported that both wild black rats (Powell, 1976b) and Mongolian gerbils (Powell, 1976a) avoided shocks much more successfully under signaled vs. unsignaled avoidance in comparison to domesticated rats. In fact, under some conditions the domesticated animals received approximately the same number of shocks with the signal present as in its absence. The domesticated rats also had generally lower response rates in both studies than the black rats and gerbils.

Our explanation for the differences described above is that nondomesticated animals maintain higher levels of activation/arousal than domesticated animals, because this characteristic is selected for in the natural environment, whereas no similar selective pressure operates for domesticated animals. Activation/arousal refers to alertness and responsiveness to salient environmental stimuli. An animal in the wild that is not responsive

A version of this paper was presented at the meeting of the Psychonomic Society, St. Louis, Missouri, November 1976. The authors thank Mary M. Matzen and Doris N. Auer for their assistance in preparing the manuscript. Reprints may be obtained from Robert W. Powell, Department of Psychology, University of South Florida, Tampa, Florida 33620. Michael D. Curley is now located at the Naval Medical Research Institute, Bethesda, Maryland 20014. to salient stimuli will often be at a disadvantage, particularly if it is a member of a species subject to heavy predation, as is the case with most small rodents. In the avoidance-conditioning situation, the supposedly higher activation levels ${ }^{\circ}$ of nondomesticated animals should lead to more effective employment of the signal as a means to avoid shock. Gerbils have been bred in captivity for approximately 20 years (Monroe, 1967), whereas the domestication of rats has been underway for a considerably longer period (Barnett, 1963). Consequently, if activation/arousal is selected for in the wild, it should still be more prominent in gerbils than in domesticated rats.

The present experiment was undertaken to replicate and extend our recent comparative studies in this area, and it differed from these experiments in two principal aspects: (1) Between-groups comparisons were used throughout, whereas the earlier studies had emphasized within-subjects comparisons. This precluded the possibility of unrecognized interaction effects between conditions. (2) Two domesticated rat strains were used here, due to the repeated finding of strain differences in avoidance behavior in domesticated rats (Davis, Porter, Burton, \& Levine, 1976; Myers, 1959, 1964; Nakamura \& Anderson, 1962).

\section{METHOD}

\section{Subjects}

Seventeen hooded rats (Long-Evans strain), 8 male and 9 female, 16 albino rats (Fischer 344 strain), 8 male and 8 female, and 19 Mongolian gerbils (Meriones unguiculatus), 10 male and 9 female, were used as subjects. All animals were between 90 and 120 days old and were experimentally naive at the start of the experiment. Subjects were housed in individual cages and had free access to Purina Lab Chow and water. 


\section{Apparatus}

All subjects were studied in a Lehigh Valley small-animal test chamber, Model 1316 (197 x $203 \times 229 \mathrm{~mm})$, which was housed within a sound-attenuating chamber. A single lever was mounted at the right side of one end, $35 \mathrm{~mm}$ from the grid floor. A white panel light, located $25 \mathrm{~mm}$ directly above the lever, provided a feedback stimulus. Illumination was provided by a 7.5-W white houselight. Electric shock was supplied by a Lehigh Valley constant-current shock source, Model 1531, and tone was provided by a BRS-Foringer audio generator, Model AU-902. Data were recorded by digital counters and a Gerbrands cumulative recorder.

\section{Procedure}

A free-operant avoidance procedure (Sidman, 1953) was used with all subjects. Under this procedure, brief electric shocks were delivered every $5 \mathrm{sec}$ (shock-shock interval) in the absence of a leverpress response. Each response postponed the next shock for $20 \mathrm{sec}$ (response-shock interval). Additionally, each response was accompanied by a flash of the panel light located above the response lever. Shock duration was $.5 \mathrm{sec}$. Responses in the presence of shock did not terminate it. Approximately one-half of the subjects within each group were studied under signaled avoidance; the remaining subjects received unsignaled avoidance training. During signaled avoidance sessions, a $1.2-\mathrm{kHz}$ tone of $85 \mathrm{~dB}$ was presented $5 \mathrm{sec}$ before a scheduled shock delivery. The tone terminated either with shock onset or with the occurrence of a response.

During the first experimental session, no shocks were delivered for the initial $30 \mathrm{~min}$. Avoidance training then commenced for $60 \mathrm{~min}$ with a shock intensity of $1.0 \mathrm{~mA}$. Thereafter, experimental sessions were $90 \mathrm{~min} /$ day with a shock intensity of $1.5 \mathrm{~mA}$. Subjects were studied 5 days/week and training continued until performance stabilized, or until 20 sessions had been conducted. The stability criterion was defined as variation in the hourly shock rate within $\pm 15 \%$ of the mean rate over five consecutive sessions.

\section{RESULTS}

\section{Avoidance}

Interspecies comparisons of shock rates were the data of primary interest. The lower portion of Figure 1 shows that the gerbils had substantially lower shock rates under signaled avoidance; the albino rats and hooded rats showed little or no improvement from the unsignaled to the signaled condition. These comparisons were confirmed with Mann-Whitney $U$ tests (two-tailed), which showed that the gerbils performed significantly better with the signal present $(U=7, p<.01)$, but neither the albino rats $(U=26, p<.29)$ nor the hooded rats $(U=34, p<.50)$ showed significant differences between the conditions.

The gerbils had lower shock rates than both rat groups under the signaled procedure, as shown by a Kruskal-Wallis analysis of variance $[\mathrm{H}(2)=12.4$, $\mathrm{p}<.01]$. Although there was no overall difference between groups under signaled avoidance $[\mathrm{H}(2)=3.97$, $\mathrm{p}<.20]$, individual Mann-Whitney $U$ tests yielded a significant difference between gerbils and hooded rats $(\mathrm{U}=19.0, \mathrm{p}<.05)$, but no difference between gerbils and albino rats $(\mathrm{U}=35.5, \mathrm{p}>.10)$, or albino rats and hooded rats $(U=25.0, p>.10)$.
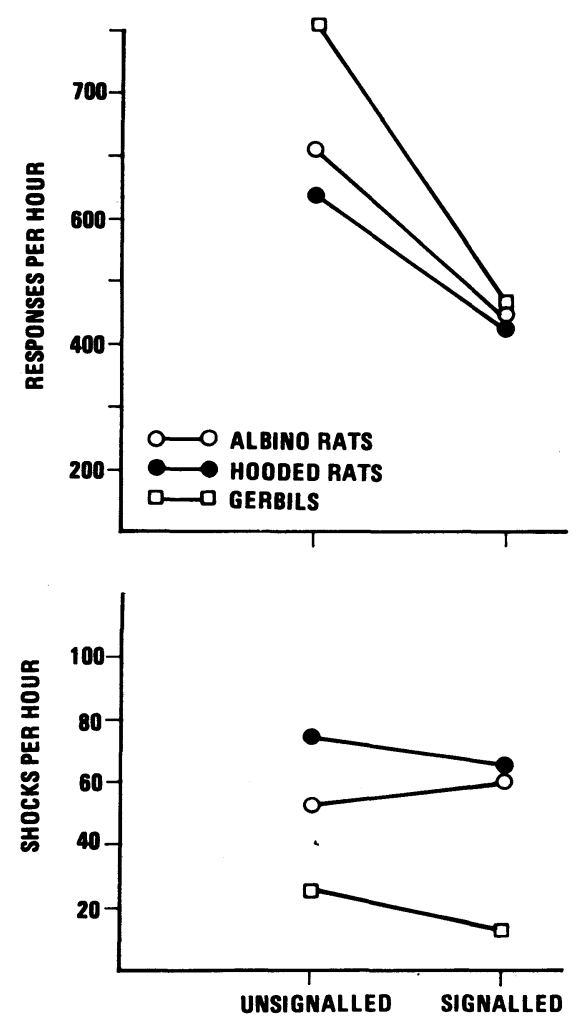

Figure 1. The number of responses and shocks per hour for each group under unsignaled and signaled avoidance. Each data point is based upon the mean performance over the final five sessions for each animal within a group.

Figure 1 shows also that there was little difference in response rates between groups under either the unsignaled $[\mathrm{H}(2)=1.85, \mathrm{p}<.50]$ or the signaled $[\mathrm{H}(2)=.88, \mathrm{p}<.70]$ condition. However, all groups had substantially lower response rates when the signal was present, as compared to the unsignaled condition (gerbils: $U=0.0, p<.002$; hooded rats: $U=5.0$, $\mathrm{p}<.002$; albino rats: $\mathrm{U}=2.0, \mathrm{p}<.002$ ).

Figure 2 presents a further analysis of the response data, in terms of the percentage of responses that occurred during the $5 \mathrm{sec}$ prior to shock when the signal was present, as compared to the $5 \mathrm{sec}$ when it was absent. Both rat groups made a substantially higher percentage of their responses during this period when the signal was present (hooded rats: $U=3.0, p<.01$; albino rats: $U=4.0, p<.01)$. It can be inferred that a similar change occurred for the gerbils, even though data for this group were not recorded under the unsignaled condition. This inference appears to be justified on the basis that the gerbils avoided shocks much more successfully under the signaled condition, even though their overall response rate decreased by approximately $50 \%$. A Kruskal-Wallis analysis comparing the three groups under the signaled condition yielded no significant differences $[H(2)=1.68, p<.50]$. All 


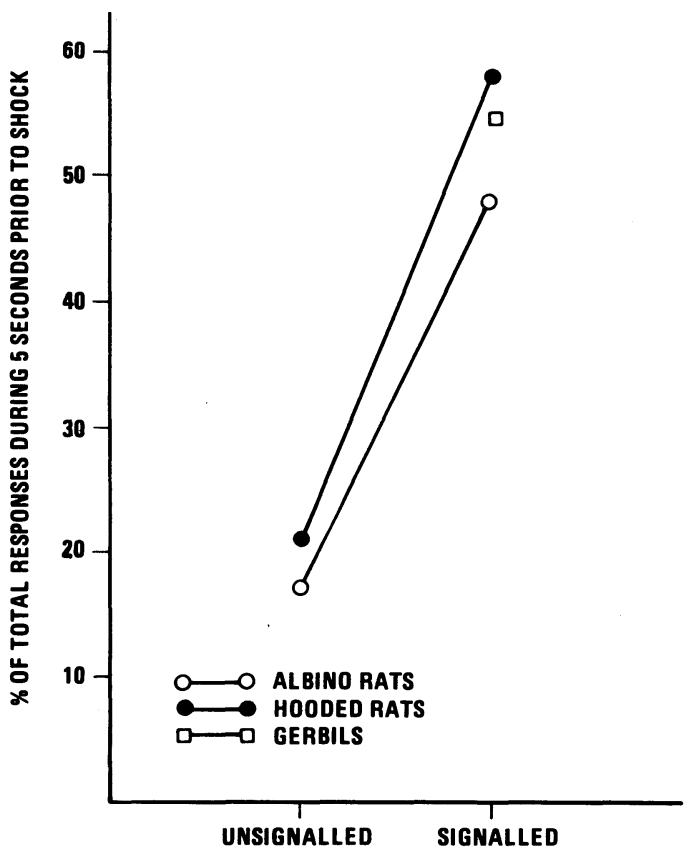

Figure 2. The percentage of responses that occurred during the $\mathbf{5}$ sec prior to shock, in relation to total session shocks, under unsignaled and signaled procedures for each group. Each data point is based upon the mean performance over the final five sessions for each animal within a group.

statistical tests were based on performance during the final five sessions under a given procedure.

The absolute number of responses that occurred during the presignal vs. the signal period under the two avoidance procedures is shown in Figure 3 (even though no signal actually occurred during unsignaled avoidance). A comparison of the upper and lower panels reveals that the principal change that occurred was a substantial decrease in the number of responses during the presignal period, from unsignaled to signaled avoidance. At the same time, there was a slight-to-moderate increase in responses during the signal period. These effects can be noted in the results for both rat groups and can be inferred to have occurred for the gerbils, based upon the consideration stated above.

\section{DISCUSSION}

The present results show again that a nondomesticated (or semidomesticated) animal, the Mongolian gerbil, avoids shocks more successfully when a preaversive signal is presented, in comparison to an unsignaled procedure. Domesticated albino rats and hooded rats, studied under the same procedures, showed no difference in shock rates under the two conditions. Thus, these dimensions of the present results are quite similar to our earlier findings (Powell, 1976a, 1976b).

The results obtained in this laboratory are not unique in finding that domesticated rats avoid no more successfully under signaled vs. unsignaled conditions (Gilbert, 1971; Logan \& Boice, 1968; Weiss, 1971). As noted earlier, a number of studies have reported that procedural and parametric variations have potent effects within this context. Berger and Brush (1975) found that domesticated rats performed poorly under signaled avoidance with brief signal-shock intervals comparable to those used here. The rats avoided much more effectively when longer signals were employed. These authors speculate that brief signals may induce freezing responses, which are incompatible with active avoidance.

Myers $(1964,1977)$ found that the type of warning signal employed had a major effect, with a buzzer resulting in much lower shock rates than a tone, a light, or no signal. It is interesting to note that differences in shock rates between the latter groups were quite small. Mean shock rates per hour were: buzzer, 10.8; tone, 21.5; light, 24.1; no signal, 27.0. Thus the difference between the buzzer and tone groups was far greater than that between the tone and no-signal groups.

The present findings appear to provide only partial support for our hypothesis that domesticated and nondomesticated animals differ in the levels of activation/arousal they maintain. Although gerbils avoided shocks much more successfully than the domesticated rats when the tone was present, the effects of the tone upon responding were quite similar for all three groups. That is, under the signaled procedure each group showed a substantial decrease in responding and an increase in both the absolute number and proportion of responses in the preshock period, in comparison to the unsignaled condition.

Myers (1977) made the rather perplexing observation that avoidance response rate increased as shock intensity increased, but the probability of responding during the signal was unaffected by shock intensity. He proposed that a warning signal does acquire a discriminative function, which improves avoidance efficiency in terms of responses per shock received, but it also acquires to some degree a response-suppressive

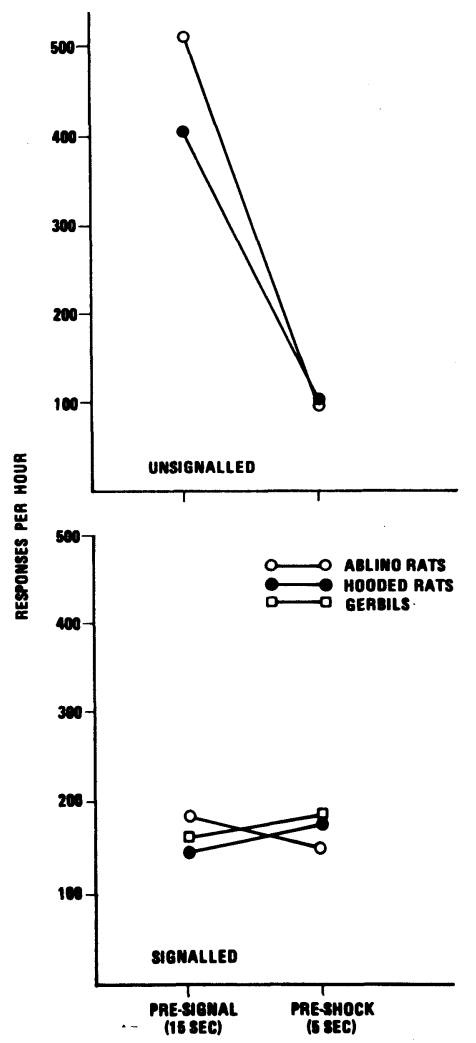

Figure 3. The number of responses per hour that occurred during the presignal vs. the signal period under unsignaled and signaled avoidance. Each data point is based upon the mean performance over the final five sessions for each animal within a group. 
tendency as a result of being a signal for shock. This inhibitory tendency is said to increase as a function of shock intensity. It is noteworthy that conditioned suppression (Estes \& Skinner, 1941) and signaled avoidance procedures both contain explicit stimulus-stimulus contingencies, but differ with respect to the response-stimulus contingency absent in the former, but present in the latter. Thus Myers may be correct in proposing that the signal acquires inhibitory or suppressive tendencies to some degree. These tendencies would be strengthened each time the subject fails to respond during a signal.

The responsc-inhibition hypothesis just noted would appear to account, plausibly, for the finding that under some conditions a signaled avoidance procedure results in little or no improvement in shock rates in comparison to an unsignaled procedure. Unsignaled avoidance lacks the explicit stimulus in close temporal relationship with shock, which could become inhibitory.

The response-inhibition hypothesis does not offer any obvious or direct explanation for the differences we have found between domesticated and nondomesticated animals. Again, the explanation may reside within the context of natural selection, which would seem to favor members of a species whose responding is facilitated by warning signals, as opposed to being inhibited by them. Such selective pressures may exist for wild stocks, but they do not appear to exist in the laboratory.

\section{REFERENCES}

Barnett, S. A. The rat. Chicago: Aldine, 1963.

BERGER, D. F., \& BRUSH, F. R. Rapid acquisition of discrete trial lever-press avoidance: Effects of signal-shock interval. Journal of the Experimental Analysis of Behavior, 1975, 24, 227-239.

Davis, H., Porter, J., Burton, J., \& Levine, S. Sex and strain differences in leverpress shock escape behavior. Physiological Psychology, 1976, 4, 351-356.

Estes, W. K., \& SkInNer, B. F. Some quantitative properties of anxiety. Journal of Experimental Psychology, 1941, 29, 390-400.
GILBERT, R. M. Signal functions in discriminated avoidance behavior. Journal of the Experimental Analysis of Behavior, 1971, 15, 97-108.

KeEHN, J. D. The effect of a warning signal on unrestricted avoidance behavior. British Journal of Psychology, 1959, 50, 125-135.

Logan, F. A., \& Boice, R. Avoidance of a warning signal. Psychonomic Science, 1968, 13, 53-54.

Monroe, B. N. Gerbils. Jersey City, New Jersey: T. F. H. Publications, 1967.

MYERS, A. K. Avoidance learning as a function of several training conditions and strain differences in rats. Journal of Comparative and Physiological Psychology, 1959, 52, 381-386.

MYERS, A. K. Discriminated operant avoidance learning in Wistar and G-4 rats as a function of type of warning stimulus. Journal of Comparative and Physiological Psychology, 1964, 58, 453-455.

MYERS, A. K. Shock intensity and warning signal effects on several measures of operant avoidance acquisition. Animal Learning \& Behavior, 1977, 5, 51-56.

Nakamura, C. Y., \& Anderson, N. H. Avoidance behavior differences within and between strains of rats. Journal of Comparative and Physiological Psychology, 1962, 55, 740-747.

Powell, R. W. A comparison of free-operant shuttle avoidance in Mongolian gerbils and albino rats. Behavioral Biology, 1976, 18, 393-399. (a)

Powell, R. W. A comparison of signaled vs. unsignaled freeoperant avoidance in wild and domesticated rats. Animal Learning \& Behavior, 1976, 4, 279-286. (b)

Sidman, M. Two temporal parameters of the maintenance of avoidance behavior by the white rat. Journal of Comparative and Physiological Psychology, 1953, 46, 253-261.

Sidman, M. Some properties of the warning stimulus in avoidance behavior. Journal of Comparative and Physiological Psychology, 1955, 48, 444-450.

WEISS, J. M. Effects of coping behavior in different warning signal conditions on stress pathology in rats. Journal of Comparative and Physiological Psychology, 1971, 72, 1-13.

(Received for publication August 7, 1978.) 